\title{
Are New Residency Graduates Prepared to Treat Opioid Use Disorder?
}

\author{
Sarab R. Burbank, BS, Rush Medical College \\ Ann Fam Med 2018;16(5):iii. https://doi.org/10.1370/afm.2306.
}

The Annals of Family Medicine encourages readers to develop a learning community to improve health care and health through enhanced primary care. Participate by conducting a RADICAL journal club. RADICAL stands for Read, Ask, Discuss, Inquire, Collaborate, Act, and Learn. We encourage diverse participants to think critically about important issues affecting primary care and act on those discussions. ${ }^{1}$

\section{HOW IT WORKS}

In each issue, the Annals selects an article and provides discussion tips and questions. Take a RADICAL approach to these materials and post a summary of your conversation in our online discussion. (Open the article and click on "TRACK Discussion/ Submit a comment.") Discussion questions and information are online at: http://www.AnnFamMed.org/site/AJC/.

\section{CURRENT SELECTION}

\section{Article for Discussion}

Tong ST, Hochheimer CJ, Peterson LE, Krist AH. Buprenorphine provision by early career family physicians. Ann Fam Med. 2018;16(5):443-446.

\section{Discussion Tips}

Buprenorphine (and methadone) use are associated with substantial reductions in mortality among individuals with opioid use disorder. ${ }^{2}$ However, there have been low rates of treatment and likely inadequate availability of opioid agonist therapy in the United States. To help address this important problem, Tong, et al start laying a path forward by describing early career family physicians' preparedness to provide and provision of buprenorphine. ${ }^{3}$

\section{Discussion Questions}

- What question is asked and why does it matter?

- How does this study advance beyond previous research (including the authors' previous work on this topic ${ }^{4}$ )?

- How strong is the study design for answering the question?
- To what degree can the findings be accounted for by: how survey respondents were selected recall bias; or chance?

- What are the main study findings?

- What role could geography play in determining resident preparedness to provide buprenoprhine? Does the study have enough granularity to comment on geographic locations?

- What role could resident engagement in research or practice-based research activities play in determining resident preparedness to provide buprenoprhine?

- How could residents selecting a program based on educational opportunities and their desire to prescribe buprenorphine affect the results?

- Is there a demand for buprenorphine in your patient population?

- What barriers to prescribing buprenorphine can you identify in your practice or local community?

- How might this study change your practice? Policy? Education? Research?

- Would an isolated policy change affecting only residency education have an effect on downstream prescribing?

- Who are the constituencies for the findings, and how they might be engaged in interpreting or using the findings?

- What are the next steps in interpreting or applying the findings?

- What researchable questions remain?

\section{References}

1. Stange KC, Miller WL, McLellan LA, et al. Annals Journal Club: It's time to get RADICAL. Ann Fam Med. 2006;4(3):196-197.

2. Sordo L, Barrio G, Bravo MJ, et al. Mortality risk during and after opioid substitution treatment: systematic review and meta-analysis of cohort studies. BMJ 2017;357:j1550.

3. Tong ST, Hochheimer CJ, Peterson LE, Krist AH. Buprenorphine provision by early career family physicians. Ann Fam Med. 2018;16(5): 443-446.

4. Tong S, Sabo R, Aycock R, et al. Assessment of addiction medicine training in family medicine residency programs: a CERA study. Fam Med. 2017:49:537-543. 